\title{
Anxiolytic, antidepressant and anti-inflammatory activities of water-soluble extract of beehive in Swiss albino mice
}

\author{
Abu Montakim Tareq ${ }^{1}$, A.S.M. Ali Reza ${ }^{1, *}$, Talha Bin Emran ${ }^{2, *}$ \\ ${ }^{1}$ Department of Pharmacy, International Islamic University Chittagong, Kumira, Chittagong-4318, \\ Bangladesh; ${ }^{2}$ Department of Pharmacy, BGC Trust University Bangladesh, Chittagong-4381, Bangladesh; \\ *Correspondence: alirezaru@gmail.com (A.S.M.A.R.); talhabmb@bgctub.ac.bd (T.B.E.);
}

\begin{abstract}
Water-soluble extract of beehive (WSE-BH) is a gummy semisolid bioactive content of Apis cerana indica beehive. The current experiment aimed to determine the anxiolytic, antidepressant, and anti-inflammatory activities of WSE-BH, which extracted using distilled water. Anxiolytic and antidepressant activities examined using elevated plus maze (EPM), hole-board test (HBT), and forced swimming test (FST), tail suspensions test (TST), respectively in Swiss albino mice (27-32 g) of both sexes. Histamine-induced paw edema used for its anti-inflammatory activity of WSE-BH during acute inflammation induced in mice. The oral administration of WSE-BH (50 \& $150 \mathrm{mg} / \mathrm{kg}$ ) showed significant anxiolytic activities through time spent (30.80 and $38.19 \%$ ) and entry $(47.16$ and $53.89 \%)$ in the open arm of EPM. In HBT, only $150 \mathrm{mg} / \mathrm{kg}$ exhibited a significant mean number of head dipping $(7.53$ times $/ \mathrm{min} ; P<0.01)$ vs. diazepam (12.87 times/min; $P<0.0001)$. In FST and TST, both 50 and $150 \mathrm{mg} / \mathrm{kg}$ exhibited a significant $(P<0.0001)$ reduction in immobility comparable to imipramine hydrochloride. WSE-BH produced a significant inhibition of histamine-induced paw edema starting at $60 \mathrm{~min}$ time point, with a maximal percentage of inhibition (80.12\%) achieved with a dose of $150 \mathrm{mg} / \mathrm{kg}$ at $180 \mathrm{~min}$ time point. The current results suggested that WSE-BH has promising anxiolytic, antidepressant, and anti-inflammatory activities.

Keywords: Apis cerana indica beehive; anxiolytic; antidepressant.
\end{abstract}

\section{MATERIALS \& METHODS}

1.1. Anxiolytic activity

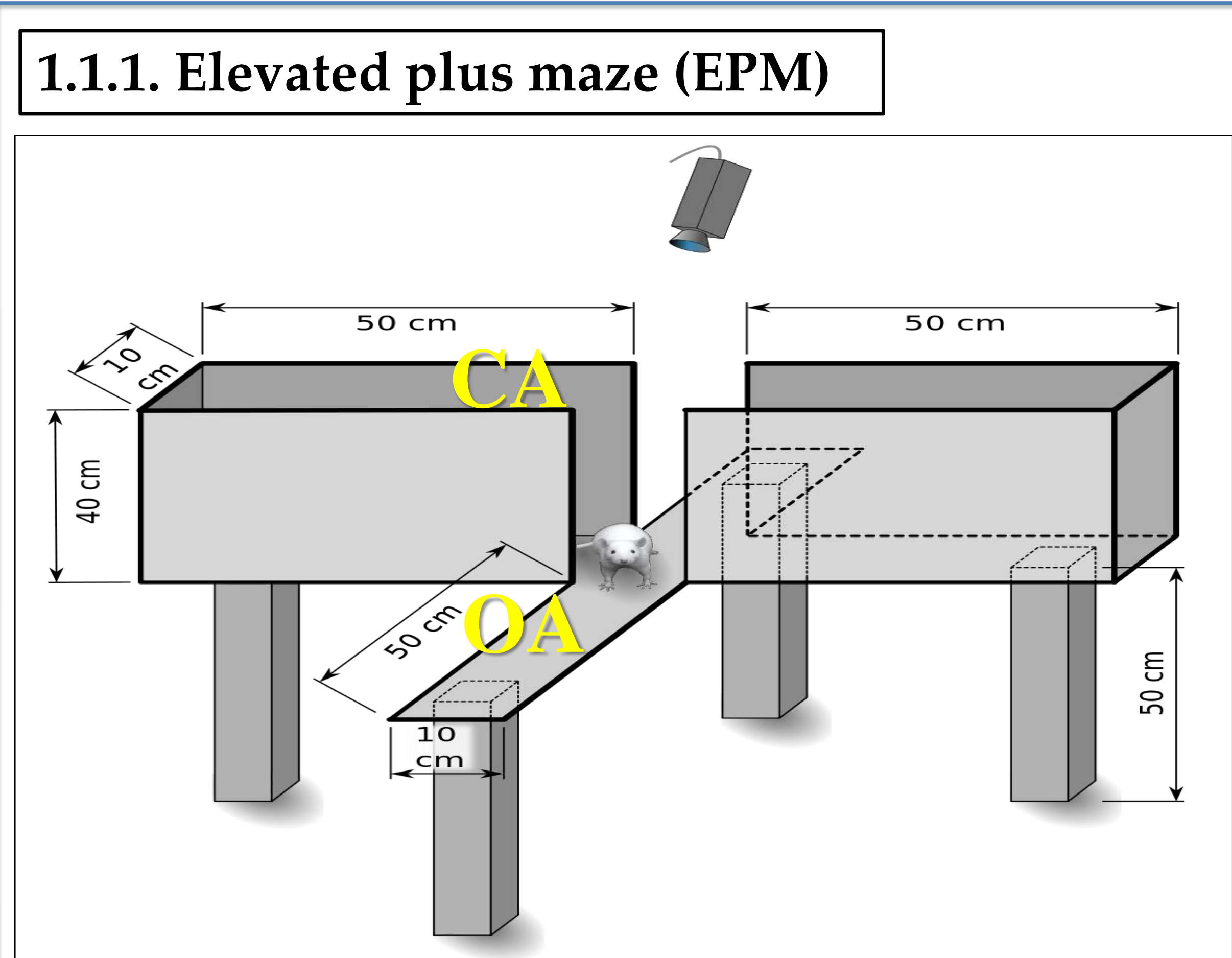

CA=Closed Arm; OA = Opened Arm

WSE-BH = $50 \& 150 \mathrm{mg} / \mathrm{kg}$ b.w., Diazepam $=1 \mathrm{mg} / \mathrm{kg} \mathrm{b.w.} \mathrm{\&} \mathrm{Control}(10 \mathrm{~mL} / \mathrm{kg})$, Time $=5 \mathrm{~min} / \mathrm{trial}$ 1.2. Antidepressant activity

\subsubsection{Tail suspension test (TST)}

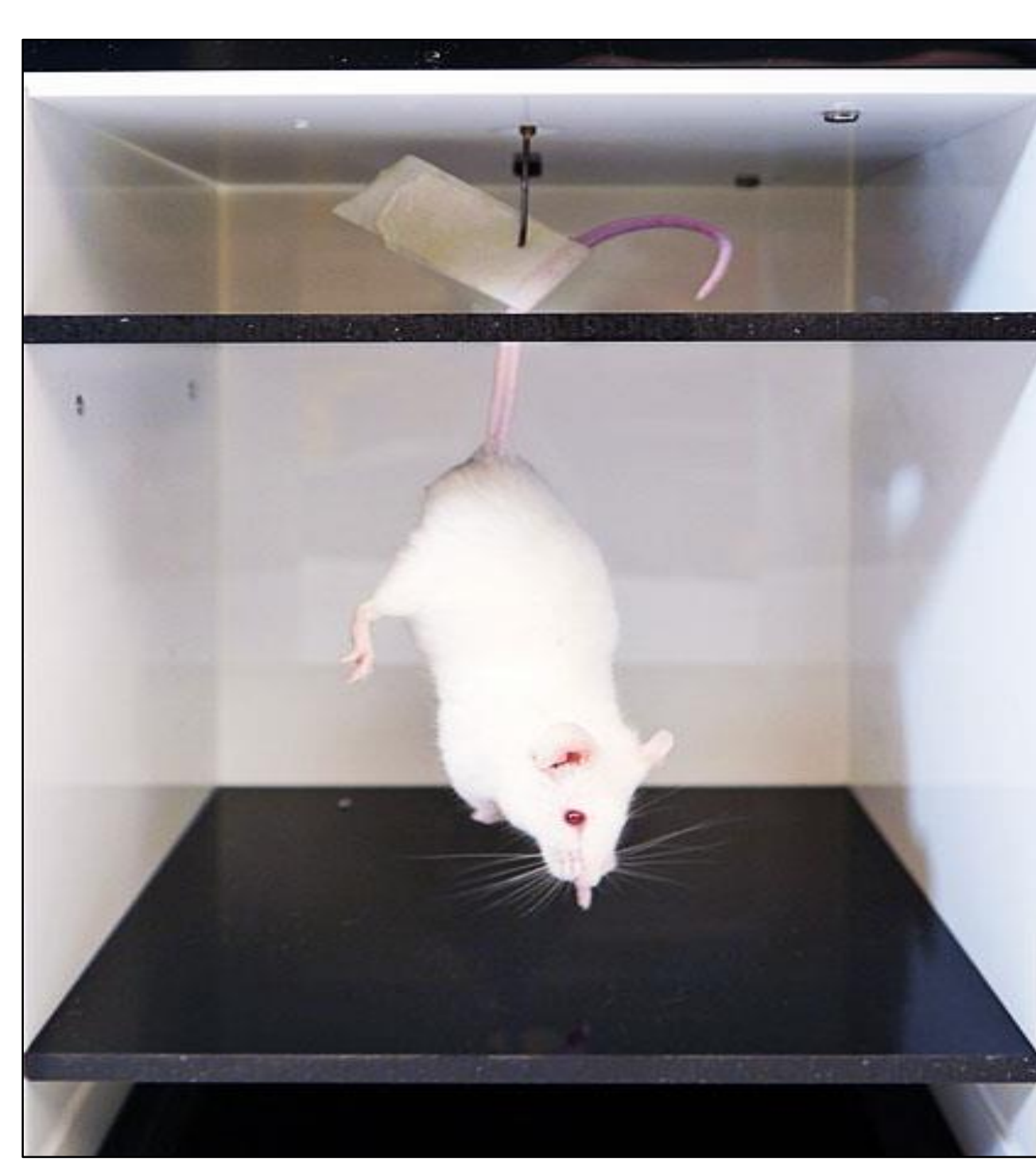

1.1.2. Hole board test (HBT)

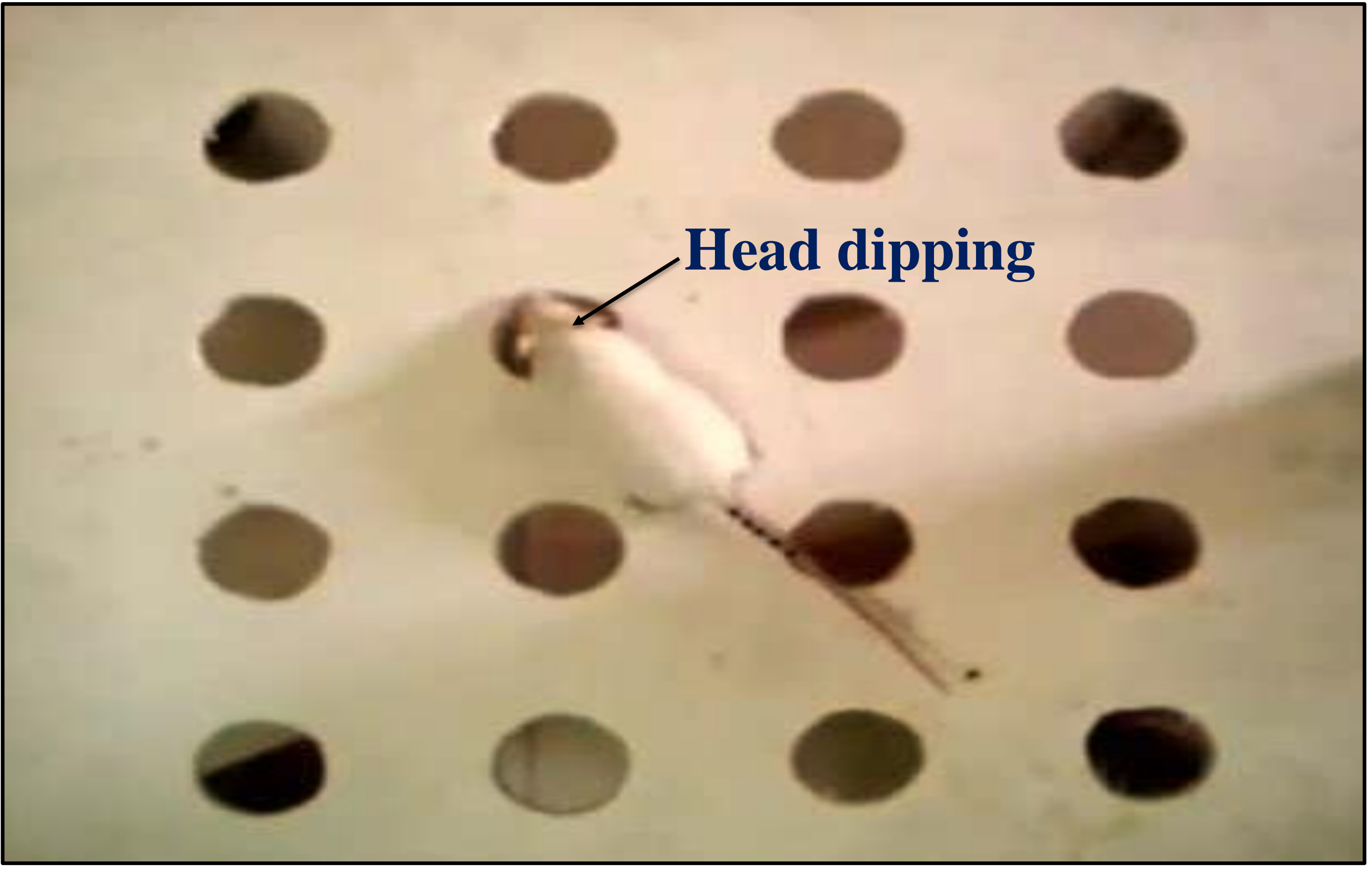
al 